\title{
Diversity Study of Nitrate Reducing Bacteria from Soil Samples - A Metagenomics Approach
}

Jha Priyanka and Mukherjee Koel*

Department of Bio-Engineering, Birla Institute of Technology, Mesra, Jharkhand, India

\begin{abstract}
The nitrogen cycle is one of the most important nutrient cycles in terrestrial ecosystems. Environmental bacteria maintain the global nitrogen cycle by metabolizing organic as well as inorganic nitrogen compounds. It is thought that most of the microbial taxa cannot be cultured outside of their natural environment, thus, microbial diversity remains poorly described before a decade. But the metagenomic techniques developed recently have therefore greatly extended our knowledge of microbial genetic diversity. The objective of this work was to analyze the taxonomic composition of three metagenome communities from the soil sample mainly rain forest, temperate broadleaf and temperate grassland via MG-RAST. Using the M5NR database, the affinities were tested for the sequences of known metabolic function against both SEED subsystems and KEGG metabolic pathways using a maximum e-value of $1 e^{-5}$. Although there are a number of metabolic functions that can be tested but we probed particularly for enzymes related to the components of nitrogen cycle. The results explain the potential taxonomic diversity of nitrate reducing bacteria with the dominance of Bradyrhizobium japonicum from soil sample.
\end{abstract}

Keyword: Metagenome; Metagenomics; MG-RAST; Nitrate reducing bacteria

\section{Introduction}

Soils cover almost all of the terrestrial area on the Earth and have indispensable ecological functions in the global carbon cycle, nitrogen cycle and sulfur cycle. Due to their physico-chemical complexity with many micro-niches, they teem with bio-diversity, both phylogenetically and functionally $[1,2]$. A single gram of soil has been estimated to contain thousands to millions of different bacterial, archaeal and eukaryotic species ${ }^{2}$ interwoven in extremely complex food webs. Communities of soil microbes carry out a multitude of very small-scale processes that underlie many environmentally important functions [3].

As nitrogen is one of the essential elements for all living organisms, the availability of a suitable nitrogen source often limits primary productivity of both natural environments and agriculture. Nitrogen levels in the environment are affected by an interacting web of processes, which are including the oxidation of ammonium and nitrite (nitrification), the dissimilatory reduction of nitrate $\left(\mathrm{NO}_{3}^{-}\right)$to ammonium $\left(\mathrm{NH}_{3}\right)$ (nitrate ammonification), and the dissimilatory reduction of nitrate via nitrite $\left(\mathrm{NO}_{2}^{-}\right)$and gaseous nitrogen oxides $\left(\mathrm{NO}_{\mathrm{x}}\right)$ to dinitrogen gas $\mathrm{N}_{2}$ (denitrification) [4]. Nitrogen $(\mathrm{N})$ can be found in several oxidation states, from +5 in the most oxidized compound (nitrate $\mathrm{NO}_{3}^{-}$) to -3 in the most reduced form (ammonium $\mathrm{NH}_{4}^{+}$), but in biological compounds it is almost exclusively present in the fully reduced state [5].

The nitrogen cycle is one of the most important nutrient cycles in terrestrial ecosystems. Nitrogen cycling involves four key microbiological processes: nitrogen fixation, mineralization (decay), nitrification and denitrification [1]. Microorganisms play very important roles in the nitrogen cycles of various ecosystems. Research has revealed that a greater diversity of microorganisms is being involved in the nitrogen cycle than previous knowledge [6]. It is becoming clear that denitrifying fungi, anammox bacteria, nitrifying archaea [7] aerobic denitrifying bacteria and heterotrophic nitrifying microorganisms are key players in the nitrogen cycle [1].

Environmental bacteria maintain the global nitrogen cycle by metabolizing organic as well as inorganic nitrogen compounds.
Denitrification is critical for maintenance of the global nitrogen cycle, through which nitrate $\left(\mathrm{NO}_{3}^{-}\right)$or nitrite $\left(\mathrm{NO}_{2}^{-}\right)$is reduced to gaseous nitrogen forms such as $\mathrm{N}_{2}$ and nitrous oxide $\left(\mathrm{N}_{2} \mathrm{O}\right)$ [5]. It is thought that most of the microbial taxa cannot be cultured outside of their natural environment; thus, microbial diversity remains poorly described. The explicit functional and ecological roles of individual taxa remain unknown because most microbes withstand laboratory cultivation [8]. Therefore the most basic questions in microbial ecology is that about "who" and "what". While soils seem to be harbor [3] for the most complex microbial communities, these considerations apply to many other environments as well, like e.g. oceans and sediments [9]. The metagenomic techniques [10] developed recently have therefore greatly extended our knowledge of microbial genetic diversity [11]. With metagenomic technologies new dimensions in the characterization of complex microbial communities have been reached [12]. A large scale shotgun sequencing approaches will able the discovery of many novel genes found in the environments and which are independent of cultivation techniques [13].

In this study we used web based server, MG-RAST (Metagenomics RAST) http://metagenomics.anl.gov/ for metagenomic analysis which is an automated analysis platform for metagenomes providing quantitative insights into microbial populations based on sequence data [14]. Metagenome samples were analyzed for the taxonomic composition with the MG-RAST server using similarity to a large non-redundant protein database; M5NR. Using the same nonredundant database, affinities were also tested for the sequences for known metabolic function against both SEED subsystems and KEGG

${ }^{*}$ Corresponding author: Koel Mukherjee, Department of Bio-Engineering, Birla Institute of Technology, Mesra, Jharkhand, India, Tel: 9572658876; E-mail: koelmukherjee@bitmesra.ac.in

Received May 05, 2015; Accepted May 23, 2015; Published May 25, 2015

Citation: Priyanka J, Koel M (2015) Diversity Study of Nitrate Reducing Bacteria from Soil Samples - A Metagenomics Approach. J Comput Sci Syst Biol 8: 191 198. doi: $10.4172 /$ jcsb. 1000188

Copyright: (c) 2015 Priyanka J, et al. This is an open-access article distributed under the terms of the Creative Commons Attribution License, which permits unrestricted use, distribution, and reproduction in any medium, provided the original author and source are credited. 
metabolic pathways using a maximum e-value of $1 \mathrm{e}^{-5}$ [15]. Although there are a number of metabolic functions that can be tested but specific interest was focused on the microbial contributions at the level of nitrate reduction in nitrogen metabolism. Thus, enzymes were selected particularly to this area only.

\section{Materials and Methods}

\section{Selection of metagenomes}

For this study metagenomes were selected from MG-RAST server (http://metagenomics.anl.gov/) public. Mainly three parameters were taken as consideration for the selection of metagenomes respectively environment (material), environment (biome) and sequence type. Mainly the Rain forest, temperate broadleaf and temperate grassland type of soil was chosen. Whole genome shotgun sequence in sequence type was selected to have an idea of microbes present in metagenomes.

\section{Analysis of the taxonomic abundance}

Abundance is the measurement of large number of individuals in a given sample. The analysis for the taxonomic abundance on selected metagenomes was carried over by different parameters like database for annotation sequence (M5NR), e-value and percentage identity cut-off and alignment length. The e-value and percentage identity cutoff were set at $1 \mathrm{e}^{-5}$ and $60 \%$. Alignment length of 45 was set for minimum length of matching aligned sequences in amino acid for proteins and base pair for RNA database.

\section{Characterization of functional attributes}

Characterization of functional attributes related to nitrogen metabolism, the MG-RAST server was used with the following parameters as hierarchical classification, subsystems and others. COG, NOG, SEED and etc databases were selected to find out the abundances that support relationship between functions. To compare annotated sequences, subsystem database was chosen. The values for the other

\begin{tabular}{|l|l|l|}
\hline SI No. & Name & MG-RAST ID \\
\hline 1. & Luquillo Experimental Forest Soil, Puerto Rico & 4446153.3 \\
\hline 2. & 002006_Sedgewick_ACTGAT_filtered_merged.fastq & 4508941.3 \\
\hline 3. & $\begin{array}{l}\text { METASOIL J1 Rothamsted 2009 July 0-21cm Direct } \\
\text { MPBIO1O1 }\end{array}$ & 4453261.3 \\
\hline
\end{tabular}

Table 1: List of metagenomes from different source. The table shows the MGRAST id for selected three metagenomes along with their names from the server. parameters like e-value, percentage identity cutoff and alignment length were the same as used in taxonomic abundance.

\section{Pathway detection}

For the pathway detection related to functional aspect (nitrate metabolism) in a metagenome, the KEGG map tool of the MG-RAST server used and the parameters were selected as follows: Database for annotation sequence comparison (subsystems), Maximum probability of a sequence with higher similarity to target sequence than one provided (e-value set to $1 \mathrm{e}^{-5}$ ), Minimum percent identity between selected metagenome with existing sBLAT sequences (percentage identity cutoff $60 \%$ ), Minimum length of matching sequence in amino-acids for proteins and base pairs for RNA database (alignment length of 45).

\section{Results and Discussion}

In continuation to the earlier discussion about parameters, in the material and method section three metagenomes (Table 1) from different soil samples were selected. Soil borne microorganisms are one of the earth's greatest sources of biodiversity [16], with ranging between 3000 and 11000 microbial genomes per gram of soil [17]. One gram of soil may contain up to 4,000 different species [18] however, current estimates indicate that less than $1 \%$ of these organisms are readily cultural with known cultivation techniques [19]. Because of the huge diversity of soil and its history as a source of commercially important molecules in agriculture, chemical, industrial and pharmaceutical industries, it remains the most common target for studies of functional metagenomics [20-22].

\section{Metagenome analysis}

In metagenome analysis we find out occurrence of domain, phyla and etc. All three metagenomes (Table 1) were analyzed in MG-RAST server. This open-source metagenomics RAST service provides a new paradigm for the annotation and analysis of metagenomes [14]. Which has built-in support for multiple data sources and a back end that houses abstract data types, the metagenomics RAST is stable, extensible, and freely available to all researchers. This service has removed one of the primary bottlenecks in metagenome sequence analysis - the availability of high-performance computing for annotating the data. The taxonomic analysis for the bacterial community was accomplished up to the species level via M5NR database in MG-RAST. A suitable reference using similar parameter cut-off values have been cited as well.

\begin{tabular}{|c|c|c|c|}
\hline METAGENOMES & 4446153.3 & 4508941.3 & 4453261.3 \\
\hline Upload: bp Count & $322,213,082 \mathrm{bp}$ & $1,997,174,632$ bp & $465,558,160 \mathrm{bp}$ \\
\hline Upload: Sequences Count & 782,404 & $11,066,959$ & $1,130,719$ \\
\hline Upload: Mean Sequence Length & $411 \pm 103 b p$ & $180 \pm 11 \mathrm{bp}$ & $411 \pm 117 \mathrm{bp}$ \\
\hline Upload: Mean GC percent & $59 \pm 6 \%$ & $61 \pm 7 \%$ & $61 \pm 7 \%$ \\
\hline Artificial Duplicate Reads: Sequence Count & 83,075 & 82,191 & 0 \\
\hline Post QC: bp Count & $279,379,947 \mathrm{bp}$ & $1,895,810,832 \mathrm{bp}$ & $465,558,160 \mathrm{bp}$ \\
\hline Post QC: Sequences Count & 642,197 & $10,805,789$ & $1,130,719$ \\
\hline Post QC: Mean Sequence Length & $435 \pm 73 \mathrm{bp}$ & $175 \pm 24 \mathrm{bp}$ & $411 \pm 117 \mathrm{bp}$ \\
\hline Post QC: Mean GC percent & $59 \pm 5 \%$ & $61 \pm 7 \%$ & $61 \pm 7 \%$ \\
\hline METAGENOMES & 4446153.3 & 4508941.3 & 4453261.3 \\
\hline Processed: Predicted Protein Features & 677,007 & $10,166,026$ & $1,159,527$ \\
\hline Processed: Predicted rRNA Features & 39,548 & $1,383,491$ & 6 \\
\hline Alignment: Identified Protein Features & 341,249 & $3,272,265$ & 629,343 \\
\hline Alignment: Identified rRNA Features & 178 & 6,021 & 911 \\
\hline Annotation: Identified Functional Categories & 314,106 & $2,570,983$ & 574,253 \\
\hline
\end{tabular}

Table 2: Analysis Statistics Table. Metagenomic samples included in this study with associated metadata and summary statistics described below. 
Citation: Priyanka J, Koel M (2015) Diversity Study of Nitrate Reducing Bacteria from Soil Samples - A Metagenomics Approach. J Comput Sci Syst Biol 8: 191-198. doi:10.4172/jcsb. 1000188

In the first metagenome 4446153.3, 140,207 sequences failed quality control (reads more than two standard deviations away from the mean read length are discarded). Of those, dereplication identified 83,075 sequences ( $10.6 \%$ of total) as artificial duplicate reads (ADRs). Of the 642,197 sequences (totaling $279,379,947 \mathrm{bps}$ ) that passed quality control, 637,914 (99.3\%) produced a total of 677,007 predicted protein coding regions. Of these 677,007 predicted protein features, 341,249 (50.4\% of features) have been assigned an annotation using at least one of our protein databases (M5NR) and 335,758 (49.6\% of features) have no significant similarities to the protein database (orfans). 314,106 features $(92.0 \%$ of annotated features) were assigned to functional categories (Table 2). The failure rate seems high for the first metagenome. But if we look at the class distribution of the microbial community, we can observe that the Alphaproteobacteria has been dominant in the metagenome.

In metagenome $4508941.3,261,170$ sequences failed quality control. Of those, de-replication identified 82,191 sequences $(0.7 \%$ of total) as artificial duplicate reads (ADRs). Of the 10,805,789 sequences (totaling $1,895,810,832 \mathrm{bps})$ that passed quality control, 10,223,265 (94.6\%) produced a total of $10,166,026$ predicted protein coding regions. Of these 10,166,026 predicted protein features, 3,272,265 (32.2\% of features) have been assigned an annotation using at least one of our protein databases (M5NR) and 6,893,761 (67.8\% of features) have no significant similarities to the protein database (orfans). $2,570,983$ features $(78.6 \%$ of annotated features) were assigned to functional categories (Table 2).

Table 2 also describe about the third metagenome 4453261.3, where 0 sequences failed quality control (indicates all reads are of about to mean length). Of those, dereplication identified 0 sequences $(0.0 \%$ of total) as artificial duplicate reads (ADRs). Of the 1,130,719 sequences (totaling 465,558,160 bps) that passed quality control, 1,103,922 (97.6\%) produced a total of $1,159,527$ predicted protein coding regions. Of these $1,159,527$ predicted protein features, 629,343 (54.3\% of features) have been assigned an annotation using at least one of our protein databases (M5NR) and 530,184 (45.7\% of features) have no significant similarities to the protein database (orfans). 574,253 features (91.2\% of annotated features) were assigned to functional categories.

\section{Taxonomic hits distribution}

The taxonomic classification of protein-coding genes was assigned to the M5NR (non-redundant protein database) annotation source using the best hit classification of MG-RAST [14]. Figure 1 showed that bacterial sequences dominated in all three samples with 97.0\% (4446153.3), 97.0\% (4508941.3) and 95.9\% (4453261.3) of all annotated sequences. Simultaneously a low number of eukaryotic $1.6 \%$ (4446153.3), $1.7 \%$ (4508941.3), $2.8 \%(4453261.3)$ as well as $1.2 \%$ (4446153.3), 1.0\% (4508941.3), 1.1\% (4453261.3) of Archaea and other sequences were also found (Table 3 ). Figure 2 illustrates the individual

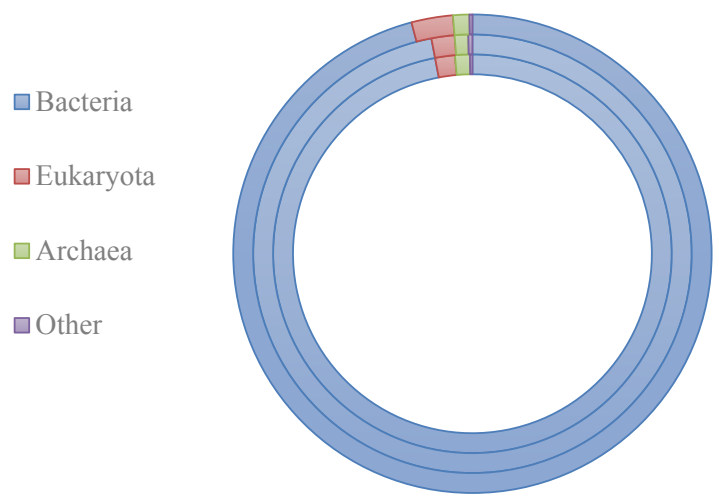

Figure 1: Combined taxonomic domain information of metagenomes. Total DNA sequences were assigned to Bacteria, Eukaryota, Archaea, viruses, and other sequences.

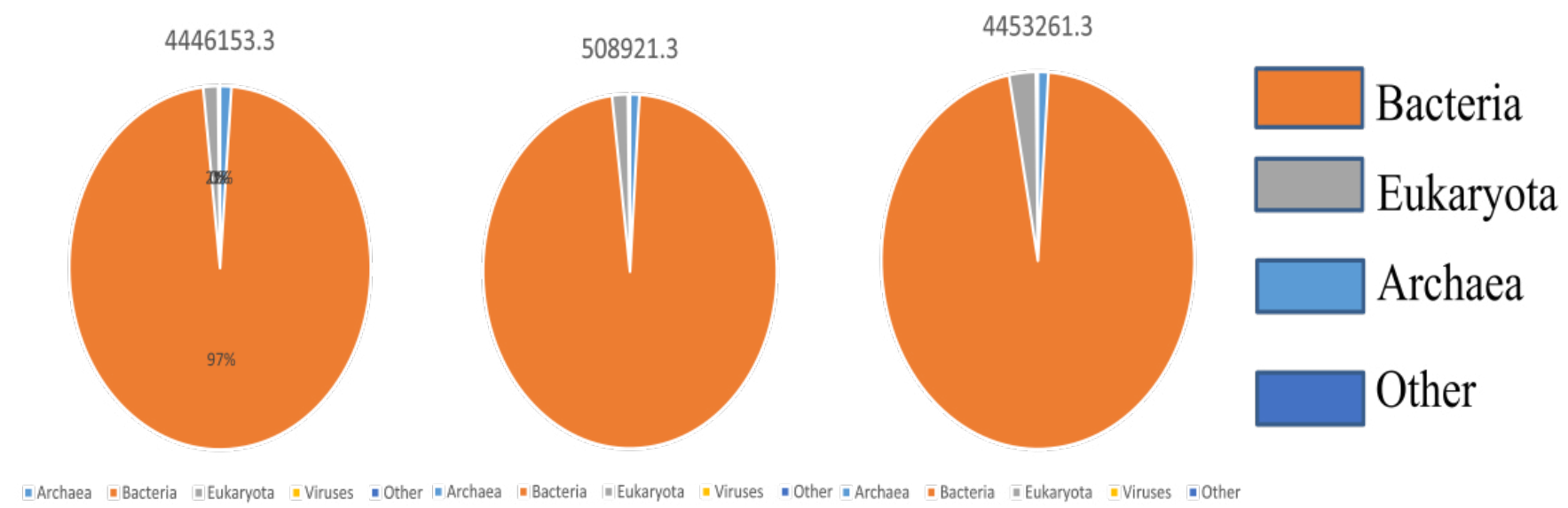

Figure 2: The pie charts below illustrate the distribution of taxonomic domains, phyla, and orders for the annotations. Each slice indicates the percentage of reads with predicted proteins and ribosomal RNA genes annotated to the indicated taxonomic level. This information is based on all the annotation source databases used by MG-RAST. 


\begin{tabular}{|l|c|c|c|}
\hline Metagenome (MG-RAST id) & 4446153.3 & 4508941.3 & 4453261.3 \\
\hline Bacteria & $97 \%$ & $97 \%$ & $95.9 \%$ \\
\hline Eukaryota & $1.6 \%$ & $1.7 \%$ & $2.8 \%$ \\
\hline Archaea & $1.2 \%$ & $1 \%$ & $1.1 \%$ \\
\hline Other & $0.2 \%$ & $0.3 \%$ & $0.2 \%$ \\
\hline
\end{tabular}

Table 3: Percentage value (\%) of Bacteria, Archaea, and Eukaryota in annotated selected there metagenome sequences.

taxonomic hit distribution of all three selected metagenomes. It was clear from the figure that Bacteria were dominating the others with highest value.

When the taxonomic composition of the samples was compared to each other (with respect to nitrate reduction), they were similar at higher taxonomic organization, but differed slightly in the composition of lower taxonomic groupings Gamma-proteobacteria and Alphaproteobacteria were dominated all samples. The microbes in all selected metagenomes showed both a taxonomic and functional composition that reflects a nitrate reduction [23]. Bradyrhizobium japonicum have the capacity to rapidly denitrify nitrate in soils under anaerobic conditions, Rhodobacter sphaeroides are able to completely denitrify nitrate to dinitrogen $\left(\mathrm{N}_{2}\right)$. In all 3 metagenomes Bradyrhizobium japonicum has been found to be the most abundant followed by Pseudomonas aeruginosa, Pseudomonas putida, Rhodobacter sphaeroides (Table 4). Presence of Escherichia coli, Paracoccus denitrificans, Bacillus subtilis, Azotobacter vinelandii, Klebsiella pneumonia, Pseudomonas stutzeri, Roseobacter denitrificans, Clostridium perfringens, Rhodobacter capsulatus, Shewanella denitrificans, Pseudomonas denitrificans, Achromobacter denitrificans were also found.

The Gamma proteobacteria were more abundant and were identified with Azotobacter vinelandii, Azotobacter chroococcum, Pseudomonas aeruginosa, Pseudomonas denitrificans, Shewanella denitrificans, Klebsiella pneumonia, Escherichia coli (Table 4) which are nitrate reducers [23]. The Alphaproteobacteria were dominated by Rhodobacter capsulatus, Rhodobacter sphaeroides, Roseobacter denitrificans, Bradyrhizobium japonicum [24] which are nitrate reducing spices [25]. Out of which Roseobacter denitrificans were absent in metagenome 4508941.3. Achromobacter denitrificans sp. of the Betaproteobacteria was present in both 4446253.3 and 4508941.3; Clostridium perfringens sp. of class Clostridia and Bacillus subtilis sp. of class Bacilli were also present in all three metagenome samples.
The observation of B. japonicum dominance has been found to be similar to the results of VanInsberghe et al. and Ormenno-Orrilli et al. [26,27]. Similarly, Delmont et al. also describes the statistical view of functional distributions of the Rothamsted soil metagenome, which aided the knowledge about soil microbial communities at a metagenomic level [28].

Nitrate is a major nitrogen source for many bacteria. In the general assimilatory pathway, nitrate is converted via nitrite to ammonia, which is then assimilated into nitrogen metabolism [29]. This metabolic route functions aerobically and anaerobically and involves assimilatory nitrate reductases which are repressed by ammonia. Nitrate can also serve as an electron acceptor for anaerobic respiration in the absence of oxygen. In this case nitrate is reduced by respiratory nitrate reductases to nitrite, the end product of nitrate respiration is denitrogen. This denitrification pathway involves [24], in addition to the respiratory nitrate reductase, further respiratory reductases for nitrite, nitric oxide, and nitrous [30]. Assimilatory nitrate reductases were found in bacteria like Azotobacter chroococcum, Clostridium perfringens, and Ectothiorhodospira shaposhnikovii (Ferredoxin-Nas) Klebsiella pneumonia and Rhodobacter capsulatus (NADH-dependent).

Mainly three different types of nitrate-reducing systems have been described in bacteria [31-33]. The first type is a cytoplasmic assimilatory nitrate reductase, which enables the utilization of nitrate as the nitrogen source for biosynthesis. This enzyme is repressed by ammonium, but is not affected by oxygen [33]. The second type is a membrane-bound respiratory nitrate reductase, which catalyses nitrate respiration and the first step of denitrification to allow ATP synthesis by using nitrate as an alternative electron acceptor under anaerobic conditions. This enzyme is repressed by oxygen, but is insensitive to ammonium [31]. Membrane-bound nitrate reductases are associated with denitrification and anaerobic nitrate respiration in Escherichia coli and Paracoccus denitrificans, (NO). The membranebound dissimilatory nitrate reductase been shown to be involved in anaerobic nitrate reduction in Paracoccus denitrificans, Pseudomonas aeruginosa, Pseudomonas denitrificans, and Pseudomonas stutzeri. The third nitrate-reducing system is a periplasmic nitrate reductase found in some Gram-negative bacteria. This enzyme is repressed by neither ammonium nor oxygen and probably participates in redox balance and/or aerobic nitrate respiration [25]. Nitrate reductases located in the periplasmic compartment have also been described in Rhodobacter capsulatus, Rhodobacter sphaeroides, Alcaligenes eutrophus, Paracoccus

\begin{tabular}{|c|c|c|c|}
\hline METAGENOMES & 4446153.3 & 4508941.3 & 4453261.3 \\
\hline CLASS & \multicolumn{3}{|c|}{ SPECIES } \\
\hline \multirow{4}{*}{ Alphaproteobacteria } & Rhodobacter capsulatus & Rhodobacter capsulatus & Rhodobacter capsulatus \\
\hline & Rhodobacter sphaeroides & Rhodobacter sphaeroides & Rhodobacter sphaeroides \\
\hline & Roseobacter denitrificans & - & Roseobacter denitrificans \\
\hline & Bradyrhizobium japonicum & Bradyrhizobium japonicum & Bradyrhizobium japonicum \\
\hline Beta proteobacteria & Achromobacter denitrificans & Achromobacter denitrificans & \\
\hline \multirow{7}{*}{ Gamma proteobacteria } & Azotobacter vinelandii & Azotobacter vinelandii & Azotobacter vinelandii \\
\hline & Azotobacter chroococcum & Azotobacter chroococcum & Azotobacter chroococcum \\
\hline & Pseudomonas aeruginosa & Pseudomonas aeruginosa & Pseudomonas aeruginosa \\
\hline & Pseudomonas denitrificans & Pseudomonas denitrificans & Pseudomonas denitrificans \\
\hline & Shewanella denitrificans & Ectothiorhodospira shaposhnikovii & Shewanella denitrificans \\
\hline & Klebsiella pneumoniae & Klebsiella pneumoniae & Klebsiella pneumoniae \\
\hline & Escherichia coli & Escherichia coli & Escherichia coli \\
\hline Clostridia & Clostridium perfringens & Clostridium perfringens & Clostridium perfringens \\
\hline Bacilli & Bacillus subtilis & Bacillus subtilis & Bacillus subtilis \\
\hline
\end{tabular}

Table 4: The taxonomic diversity of microbes (nitrate reducers) from the selected metagenomes. 
denitrificans, and Pseudomonas putida. Reduction of nitrate in the periplasm is not sensitive to the oxygen inhibition of nitrate transport across the cytoplasmic membrane that prevents reduction by the membrane-bound enzyme. Table 4 also describes the existence of Escherichia coli, Rhodobacter capsulatus and Rhodobacter sphaeroides which reduces nitrate to ammonium. In Pseudomonas putida a membrane-bound nitrate reductase with an active site in the cytoplasm. This enzyme allows the oxidation of quinol by nitrate to be coupled to the generation of a transmembrane proton electrochemical gradient and thus has an important role in energy generation under anoxic conditions.

\section{Pathway detection related to nitrate reduction in a metagenome}

Interest in nitrate reduction exists for several reasons. First, it is a major mechanism of loss of fertilizer nitrogen resulting in decreased efficiency of fertilizer use. Second, it is of great potential application in the removal of nitrogen from high-nitrogen waste materials such as animal residues. Third, nitrate reduction is an important process, contributing $\mathrm{N}_{2} \mathrm{O}$ to the atmosphere, where it is involved in stratospheric reactions which result in the depletion of ozone. Fourth, it is the mechanism by which the global nitrogen cycle is balanced. From Figures 3-5 we can say that there are three types of nitrate reducing pathways are present in all three selected metagenomes mainly dissimilatory nitrate reduction pathway, assimilatory nitrate reduction pathway and denitrification pathway.

\section{Conclusion}

Metagenomics can provide valuable insights into the functional ecology of environmental communities. Using the metagenome sequences to fully understand how complex microbial communities function and how microbes interact within these niches represents a major challenge for microbiologists today. Microorganisms play important roles in the nitrogen cycles of various ecosystems. Research has revealed that a greater diversity of microorganisms is involved in the nitrogen cycle than previously understood. It is becoming clear that denitrifying fungi, nitrifying archaea, anammox bacteria, aerobic denitrifying bacteria and heterotrophic nitrifying microorganisms are key players in the nitrogen cycle. From soil metagenome potential taxonomic diversity of nitrate reducing bacteria

NITROGEN METABOLISM : REDUCTION AND FIXATION

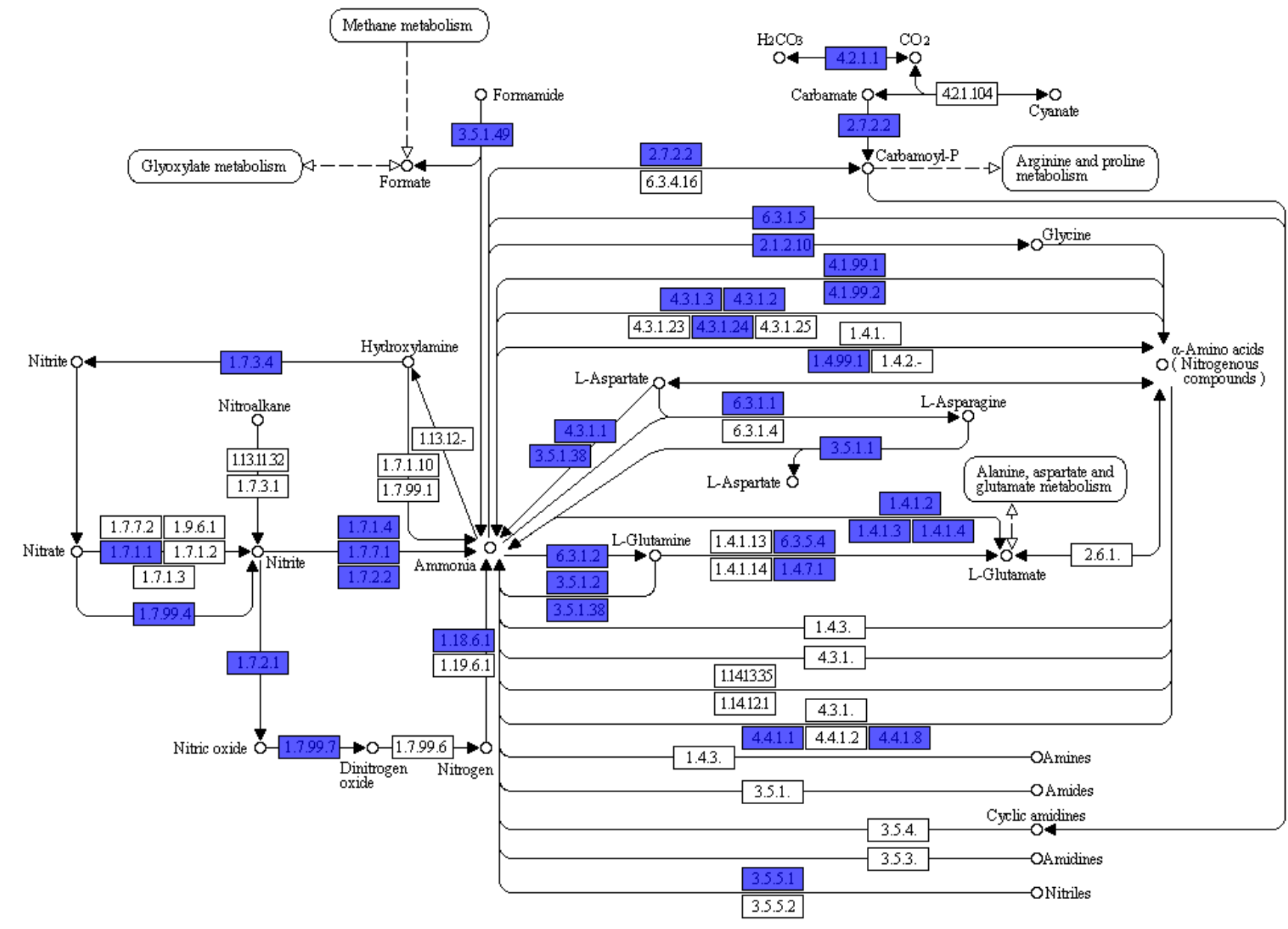


Citation: Priyanka J, Koel M (2015) Diversity Study of Nitrate Reducing Bacteria from Soil Samples - A Metagenomics Approach. J Comput Sci Syst Biol 8: 191-198. doi:10.4172/jcsb.1000188

NITROGEN METABOLISM : REDUCTION AND FIXATION

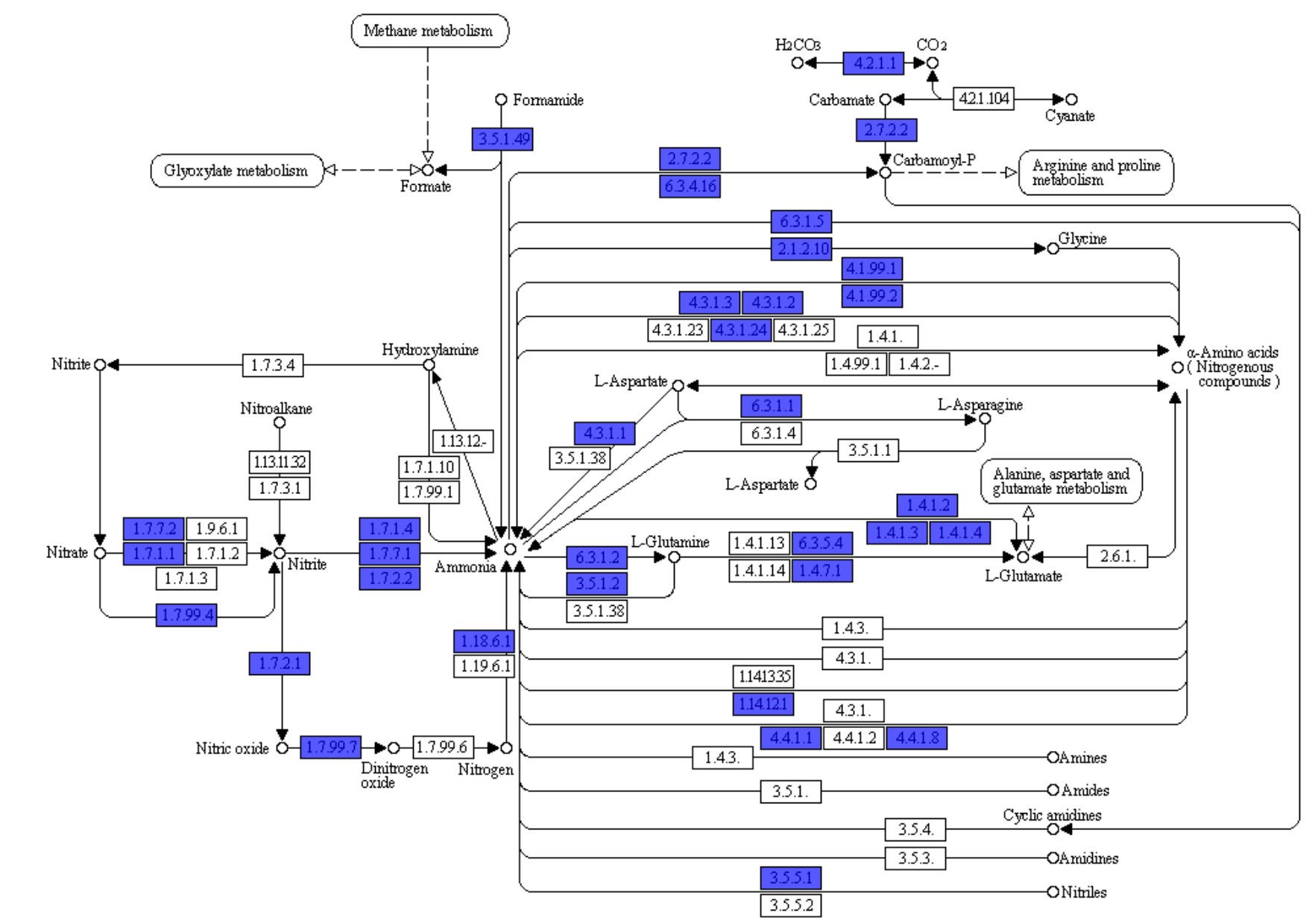

0091093009

(c) Kanehisa Laboratories

Figure 4: Nitrogen metabolism pathway in metagenome 4508941.3

with their probable activity were studied. The results explain the potential taxonomic diversity of nitrate reducing bacteria with the dominance of Bradyrhizobium japonicum from soil sample. The nitrate reducing metabolic pathway were studied and it is found that in given metagenomes all three pathways of nitrate reduction i.e. assimilatory nitrate reduction, respiratory (dissimilatory) nitrate reduction as well as dinitrification are present.

\section{Acknowledgement}

We gratefully acknowledge TEQIP-II, Birla Institute of Technology, Mesra, Ranchi, Jharkhand for providing all the facilities to carry out this work.

\section{References}

1. Masahito H, Kanako T, Masanori S (2008) Various Players in the Nitrogen Cycle: Diversity and Functions of the Microorganisms Involved in Nitrification and Denitrification. Soil Sci Plant Nutr 54: 33-45.

2. Torsvik V, Øvreås L, Thingstad TF (2002) Prokaryotic diversity--magnitude, dynamics, and controlling factors. Science 296: 1064-1066.

3. Jha P, Ghosh S, Mukhopadhyay K, Sachan A, Vidyarthi AS (2014) Diversity and Role of Sulfate Reducing Prokaryotic Communities in Coal Mines using Metagenomics. Int J Adv Life Sci 6: 297-302.
4. Hofstra N, Bouwman A (2005) Denitrification in Agricultural Soils: Summarizing Published Data and Estimating Global Annual Rates. Nutr Cycl Agroecosyst 72: 267-278.

5. Doi Y, Takaya N, Takizawa N (2009) Novel denitrifying bacterium Ochrobactrum anthropi YD50.2 tolerates high levels of reactive nitrogen oxides. Appl Environ Microbiol 75: 5186-5194.

6. Conrad R (1996) Soil microorganisms as controllers of atmospheric trace gases (H2, CO, CH4, OCS, N2O, and NO). Microbiol Rev 60: 609-640.

7. Cabello P, Roldán MD, Moreno-Vivián C (2004) Nitrate reduction and the nitrogen cycle in archaea. Microbiology 150: 3527-3546.

8. Fierer N, Bradford MA, Jackson RB (2007) Toward an ecological classification of soil bacteria. Ecology 88: 1354-1364.

9. Urich T, Lanzén A, Qi J, Huson DH, Schleper C, et al. (2008) Simultaneous assessment of soil microbial community structure and function through analysis of the meta-transcriptome. PLoS One 3: e2527.

10. Gomez-Alvarez V, Teal TK, Schmidt TM (2009) Systematic artifacts in metagenomes from complex microbial communities. ISME J 3: 1314-1317.

11. Pace NR (1997) A molecular view of microbial diversity and the biosphere Science 276: 734-740.

12. Kakirde KS, Parsley LC, Liles MR (2010) Size Does Matter: Application-driven Approaches for Soil Metagenomics. Soil Biol Biochem 42: 1911-1923. 
Citation: Priyanka J, Koel M (2015) Diversity Study of Nitrate Reducing Bacteria from Soil Samples - A Metagenomics Approach. J Comput Sci Syst Biol 8: 191-198. doi:10.4172/jcsb.1000188

NITROGEN ME TABOLISM : REDUCTION AND FIXATION

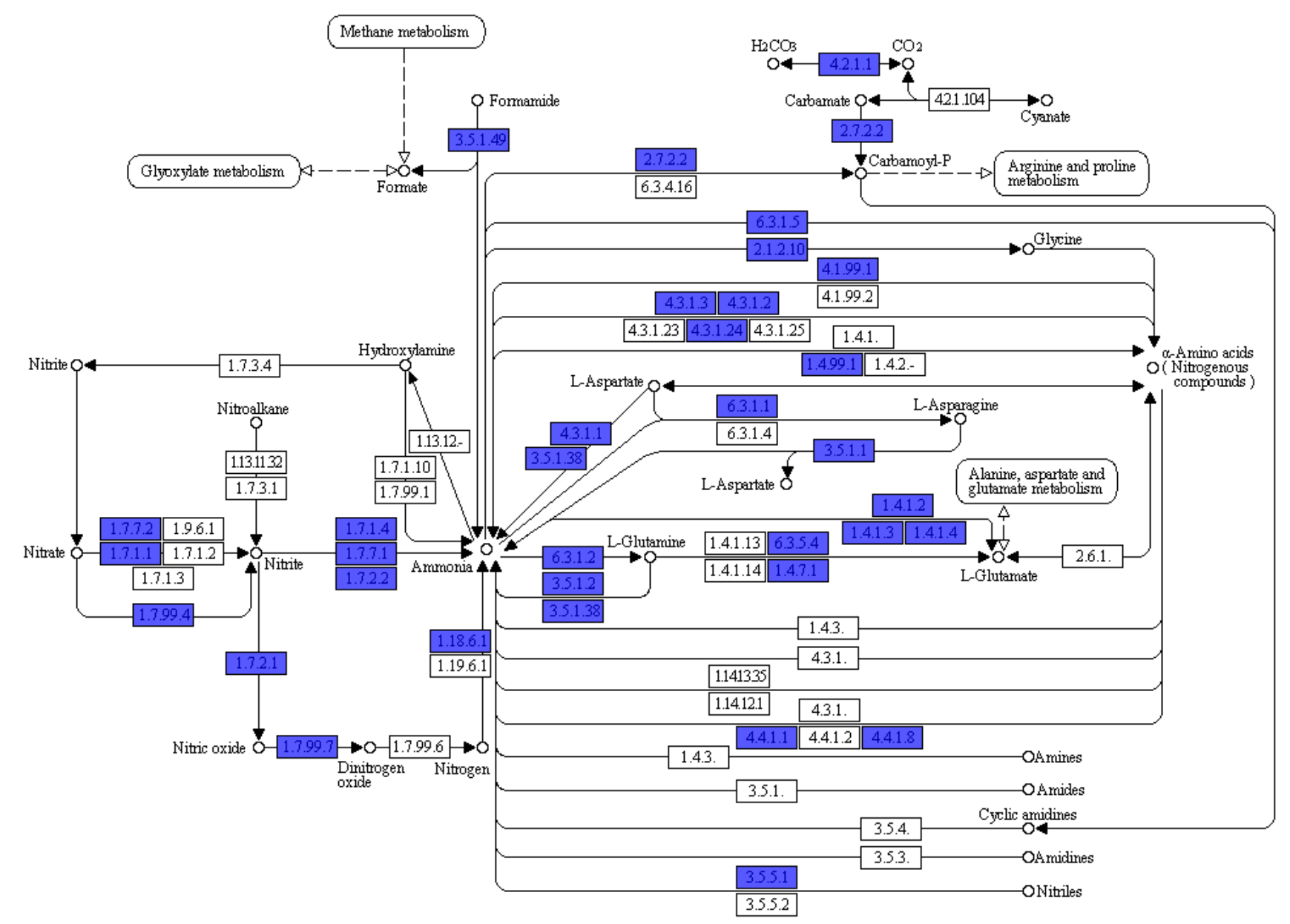

$009109 / 30 / 09$

(c) Kanehisa I Ahnratnies

Figure 5: Nitrogen metabolism pathway in metagenome 4453261.3

13. Tringe SG, von Mering C, Kobayashi A, Salamov AA, Chen K, et al. (2005) Comparative metagenomics of microbial communities. Science 308: 554-557.

14. Wilke A, Glass EM, Bartels D, Bischof J, Braithwaite D, et al. (2013) A metagenomics portal for a democratized sequencing world. Methods Enzymol 531: 487-523.

15. Mitra S, Rupek P, Richter DC, Urich T, Gilbert JA, et al. (2011) Functional analysis of metagenomes and metatranscriptomes using SEED and KEGG. BMC Bioinformatics 12 Suppl 1: S21.

16. Curtis TP, Sloan WT, Scannell JW (2002) Estimating prokaryotic diversity and its limits. Proc Natl Acad Sci U S A 99: 10494-10499.

17. Seshadri R, Kravitz SA, Smarr L, Gilna P, Frazier M (2007) CAMERA: a community resource for metagenomics. PLoS Biol 5: e75.

18. Torsvik V, Øvreås L (2002) Microbial diversity and function in soil: from genes to ecosystems. Curr Opin Microbiol 5: 240-245.

19. Amann RI, Ludwig W, Schleifer KH (1995) Phylogenetic identification and in situ detection of individual microbial cells without cultivation. Microbiol Rev 59: 143-169.

20. MacNeil IA, Tiong CL, Minor C, August PR, Grossman TH, et al. (2001) Expression and isolation of antimicrobial small molecules from soil DNA libraries. J Mol Microbiol Biotechnol 3: 301-308.
21. Courtois S, Cappellano CM, Ball M, Francou FX, Normand P, et al. (2003) Recombinant environmental libraries provide access to microbial diversity for drug discovery from natural products. Appl Environ Microbiol 69: 49-55.

22. Daniel R (2005) The metagenomics of soil. Nat Rev Microbiol 3: 470-478.

23. Bru D, Sarr A, Philippot L (2007) Relative abundances of proteobacteria membrane-bound and periplasmic nitrate reductases in selected environments. Appl Environ Microbiol 73: 5971-5974.

24. Breitenbeck A, Bremner M (1989) Ability of Free-living Bradyrhizobium japonicum to Denitrify Nitrate in Soils. Biol Fertil Soils 7: 219-224.

25. Roldan MD, Reyes F, Moreno-Vivian C, Castillo F (1994) Chlorate and Nitrate Reduction in the Phototrophic Bacteria Rhodobacter capsulatus and Rhodobacter sphaeroides. Curr Microbiol 29: 241-245.

26. VanInsberghe D, Maas KR, Cardenas E, Strachan CR, Hallam SJ, et al. (2015) Non-symbiotic Bradyrhizobium ecotypes dominate North American forest soils. ISME J.

27. Ormeño-Orrillo E, Rogel-Hernández MA, Lloret L, López-López A, Martínez $J$, et al. (2012) Change in land use alters the diversity and composition of Bradyrhizobium communities and led to the introduction of Rhizobium etli into the tropical rain forest of Los Tuxtlas (Mexico). Microb Ecol 63: 822-834.

28. Delmont TO, Prestat E, Keegan KP, Faubladier M, Robe P, et al. (2012) Structure, fluctuation and magnitude of a natural grassland soil metagenome. ISME J 6: 1677-1687. 
Citation: Priyanka J, Koel M (2015) Diversity Study of Nitrate Reducing Bacteria from Soil Samples - A Metagenomics Approach. J Comput Sci Syst Biol 8: 191-198. doi:10.4172/jcsb.1000188

29. Tiedje JM (1988) Ecology of Denitrification and Dissimilatory Nitrate Reduction to Ammonium. Biology of Anaerobic Microorganisms 717: 179-244.

30. Richardson DJ, Berks BC, Russell DA, Spiro S, Taylor CJ (2001) Functional biochemical and genetic diversity of prokaryotic nitrate reductases. Cell Mol Life Sci 58: 165-178.

31. Berks BC, Ferguson SJ, Moir JW, Richardson DJ (1995) Enzymes and associated electron transport systems that catalyse the respiratory reduction of nitrogen oxides and oxyanions. Biochim Biophys Acta 1232: 97-173.
32. Reyes F, Roldan M, Klipp W, Castillo F, Moreno-Vivian C (1996) Isolation of Periplasmic Nitrate Reductase Genes from Rhodobacter sphaeroides DSM 158: Structural and Functional Differences among Prokaryotic Nitrate Reductases. Mol Microbiol 19: 1307-1318.

33. Goldman BS, Lin JT, Stewart V (1994) Identification and structure of the nasR gene encoding a nitrate- and nitrite-responsive positive regulator of nasFEDCBA (nitrate assimilation) operon expression in Klebsiella pneumoniae M5al. J Bacteriol 176: 5077-5085. 